\title{
LRP5, low-density-lipoprotein-receptor-related protein 5, is a determinant for bone mineral density
}

Received: 7 October 2003/ Accepted: 6 November 2003/Published online: 15 January 2004

(C) The Japan Society of Human Genetics and Springer-Verlag 2004

\begin{abstract}
Osteoporosis is a multifactorial trait with low bone mineral density (BMD). We report results of an association study between BMD and nine candidate genes (TGFB1, TGFBR2, SMAD2, SMAD3, SMAD4, IFNB1, IFNARI, FOS and LRP5), as well as of a case-control study of osteoporosis. Samples for the former association study included 481 general Japanese women. Among the
\end{abstract}

T. Mizuguchi $\cdot$ Y. Watanabe $\cdot$ N. Matsumoto

N. Niikawa $\cdot$ K. Yoshiura $(\bowtie)$

Department of Human Genetics,

Graduate School of Biomedical Sciences,

Nagasaki University, Sakamoto 1-12-4,

Nagasaki 852-8523, Japan

E-mail: kyoshi@net.nagasaki-u.ac.jp

Tel.: +81-95-8497120

Fax: + 81-95-8497121

T. Mizuguchi $\cdot$ K. Tsukamoto $\cdot$ T. Ohta $\cdot$ T. Kishino

N. Matsumoto $\cdot$ N. Niikawa $\cdot$ K. Yoshiura

Core Research for Evolutional Science and Technology (CREST),

Japan Science and Technology Corporation (JST),

Kawaguchi, Japan

Y. Watanabe

Department of Obstetrics and Gynecology,

Asahikawa Medical College, Asahikawa, Japan

I. Furuta $\cdot$ H. Minakami

Department of Obstetrics and Gynecology,

Graduate School of Medicine,

Hokkaido University, Sapporo, Japan

K. Tsukamoto

Department of Clinical Pharmacy,

Graduate School of Biomedical Sciences,

Nagasaki University, Nagasaki, Japan

H. Tomita

Nagasaki Prefectural Medical Health Center,

Nagasaki, Japan

M. Tsujihata

Nagasaki Kita Hospital, Nagasaki, Japan

T. Ohta $\cdot$ T. Kishino

Division of Functional Genomics,

Center for Frontier Life Sciences,

Nagasaki University, Nagasaki, Japan nine candidate genes examined, only LRP5 showed a significant association with BMD. We identified a strong linkage disequilibrium (LD) block within LRP5. Of five $L P R 5$ single nucleotide polymorphisms (SNPs) that are located in the LD block, three gave relatively significant results: Women with the $\mathrm{C} / \mathrm{C}$ genotype at the c.2220C $>\mathrm{T}$ SNP site had higher adjusted BMD (AdjBMD) value compared to those with $\mathrm{C} / \mathrm{T}$ and $\mathrm{T} / \mathrm{T}(p=0.022)$; and likewise, $\mathrm{G} / \mathrm{G}$ at IVS17-30G $>\mathrm{A}$ and $\mathrm{C} / \mathrm{C}$ women at c.3989C $>$ T showed higher AdjBMD than those with $\mathrm{G} /$ $\mathrm{A}$ or $\mathrm{A} / \mathrm{A}(p=0.039)$ and with $\mathrm{C} / \mathrm{T}$ or $\mathrm{T} / \mathrm{T}(p=0.053)$, respectively. The case-control study in another series of samples consisting of 126 osteoporotic patients and 131 normal controls also gave a significant difference in allele frequency at c. $2220 \mathrm{C}>\mathrm{T}\left(x^{2}=6.737, p=0.009\right)$. These results suggest that $L R P 5$ is a BMD determinant and also contributes to a risk of osteoporosis.

Keywords Bone mineral density - Osteoporosis · Association study · Haplotype analysis · LRP5

\section{Introduction}

Osteoporosis, a multifactorial trait with low bone mineral density (BMD), is common among postmenopausal women who could have bone fractures in spite of minimal traumas. The BMD, a good scale to predict the risk of subsequent fractures, is regulated by both polygenes and environmental factors. Although both twin and family studies have shown that $50-80 \%$ of age-related variance of BMD are genetically determined (Eisman 1999; Stewart and Ralston 2000), genetic susceptibility to osteoporosis has not fully been understood. Previous studies demonstrated that BMD is associated with several genes/proteins. They included genes for parathyroid hormone (PTH) (Hosoi et al. 1999), alpha 1 chain of type I collagen (COL1A1) (Grant et al. 1996), vitamin D receptor $(V D R)$ (Morrison et al. 1994), transforming growth factor beta 1 (TGFB1) (Yamada et al. 1998; 
Bertoldo et al. 2000), interleukin-6 (ILO) (Ota et al. 2001), osteoprotegerin $(O P G)$ (Ohmori et al. 2002), and tumor necrosis factor receptor superfamily, member 1B (TNFRSF1B ) (Spotila et al. 2000; Albagha et al. 2002). However, conflicting results have been reported in some of them.

Analysis of a monogenic disorder, Camurati-Engelmann disease (MIM \#131300), uncovered TGF- $\beta 1$ as one regulatory factor of bone metabolism (Kinoshita et al. 2000; Saito et al. 2001). A T-to-C transition at the nucleotide position +29 in the signal sequence region of the TGF- $\beta 1$ gene $(T G F B 1)$ showed a significant association with bone mass at the lumbar spine in Japanese postmenopausal women (Yamada et al. 1998). Both Ifnb1-/- and Ifnar 1-/- mice exhibited characteristic features of osteoporosis (Takayanagi et al. 2002). Nonsense or missense mutations of LRP5, which encodes the transmembrane-spanning protein involving in the Wnt signaling pathway, caused autosomal recessive osteoporosis-pseudoglioma syndrome (OPPG, MIM \#259770) (Hey et al. 1998; Gong et al. 2001), while heterozygotes for truncation type mutations showed lower BMD than age- and gender-matched controls (Gong et al. 2001). Heterozygous glycine-to-valine substitution at codon 171 in LRP5-exon 3 was found in autosomal dominant highbone-mass trait (HBM, MIM \#601884) (Boyden et al. 2002; Little et al.2002). Therefore, all these genes may contribute to the BMD phenotype.

Here we report on the results of two association studies: a study with a series of samples between BMD and either of the candidate genes TGFB1, TGFBR2, SMAD2, SMAD3, SMAD4, IFNB1, IFNAR1, FOS and $L R P 5$; and a case-control study with the other series between osteoporosis and LRP5.

\section{Materials and methods}

Association study between $B M D$ and TGFB1, TGFBR2, SMAD2, SMAD3, SMAD4, IFNB1, IFNAR1, FOS or LRP5

\section{Subjects and their BMD values}

The subjects studied included 481 healthy Japanese women aged $54.2 \pm 12.4$ years who had a health checkup provided by the Nagasaki Prefectural Government as a population-based system. They underwent a radiological examination to be evaluated for BMD values. BMD measurements were performed at the left radial bone by dual-energy X-ray absorptiometry (DEXA) using DTX200 DexaCare (Osteometer MediTech Inc., Hawthorne, CA, USA). Because BMD is affected by many factors, differences by age, height and weight were calculated with multiple regression analysis using Statview software (SAS Institute Inc. Cary, NC, USA) and adjusted with the following correcting formulas: body mass index $(\mathrm{BMI})=$ body weight $(\mathrm{kg}) /$ body height ${ }^{2}\left(\mathrm{~m}^{2}\right)$; and adjusted BMD $($ AdjBMD $)$ value $=$ BMD $-0.00447 \times(54.23-$ age $)+0.00802 \times(22.65-$ BMI). The AdjBMD values among the samples were statistically analyzed by Student's $t$ test. Study protocols were approved by the Committee for the Ethical Issues on Human Genome and Gene Analysis at Nagasaki University. Under written, informed consent, genomic DNA was extracted from participants using the standard method.
Single nucleotide polymorphism (SNP) identification and genotyping

For TGFB1, TGFBR2, SMAD2, SMAD3, and SMAD4, we used 106 SNPs and 11 other types of variations together with their primers, reported previously (Watanabe et al. 2002). Four primers were generated to cover the IFNBI sequence between $1 \mathrm{~kb}$ upstream from the translation initiation site and $800 \mathrm{bp}$ downstream from the termination codon. Two and five primer sets were made for IFNARI and FOS, from the JSNP database (Hirakawa et al. 2002). To identify highly informative SNPs in these genes, we recruited 16 healthy Japanese volunteers other than the samples above and confirmed six SNPs in IFNB1, five in IFNAR1, and seven in FOS. SNP genotyping for TGFBI and the four other related genes was performed by the TaqMan PCR procedure (Applied Biosystems, Foster City, CA, USA). Genotype for other genes was determined by the PCR sequencing method. In short, after the amplified products were purified with ExoSAP-IT (Amersham-Pharmacia, Cleveland, OH, USA), they were subjected to sequencing using BigDye terminator kit, version 3 (Applied Biosystems) on an ABI 3100 DNA automated sequencer (Applied Biosystems). Electropherograms were aligned by Auto-Assembler software (Applied Biosystems) to detect SNPs and genotype.

A total of 23 primers were made for LRP5 to amplify all exons and exon-intron boundaries. Two other primers were also generated to verify intron 1 SNPs deposited in the GenBank and in the JSNP database. Seventy-seven samples were sequenced to identify LRP5 SNPs and genotyped by either PCR-direct sequencing or the TaqMan PCR procedure.

\section{Statistical analysis}

The 481 samples were divided into three groups according to their BMD values. Group 1 (low BMD group) consisted of 60 women with $\mathrm{BMD}<0.33 \mathrm{~g} / \mathrm{cm}^{2}$ and age $>50$ years, group 2 (high BMD group) included 46 women with BMD $>0.50 \mathrm{~g} / \mathrm{cm}^{2}$ and age $>50$ years, and group 3 was comprised of the other 375 women. As for genes involving the TGF- $\beta 1$ and interferon $\beta$ signaling pathways, we chose SNPs referring both to allele frequencies between groups 1 and 2 and to linkage disequilibrium (LD) data. When allele frequency distortion was observed between the two groups, we expanded genotyping to all 481 samples and then compared the average AdjBMD value in each genotype by Student's $t$ test. For $L R P 5$, we quantified LD, expressed as "D" and "r-square", between all pairs of biallelic loci using SNPAlyze program (Dynacom, Yokohama, Japan). The haplotype frequencies and the estimated diplotype of each individual were also calculated by SNPAlyze using genotyping data. Quantitative associations between genotypes/haplotypes and AdjBMD were analyzed by Statview software. Comparison of the average AdjBMD value in each genotype/haplotype was done by Student's $t$ test. We categorized genotypes $\mathrm{C} / \mathrm{C}, \mathrm{C} / \mathrm{T}$, and T/T at LRP5-9 in each of the 481 women into three incremental values, 0,1 , and 2 , to calculate the Spearman's correlation coefficient.

\section{Case-control study on osteoporosis and LRP5}

The samples used consisted of 126 women with osteoporosis and 131 normal control women, all of whom were admitted to the Obstetrics and Gynecology Department of Hokkaido University Hospital for cancer screening, osteoporotic risk evaluation, hormone replacement therapy, or treatment for a mild-to-moderate climacteric disorder. Medical history was obtained from all these women, and those with disorders known to affect BMD were excluded. BMD at the lumbar spine (L2-L4) was measured by dualenergy X-ray absorptiometry (DEXA) with QDR2000 instrumentation (Hologic Inc., Waltham, MA, USA). The Z-score values for lumbar BMD showing a deviation from the weight-adjusted average BMD of each age were calculated based on the previously reported data for the general Japanese women (Soda et al. 1993). 
Diagnosis was made under the World Health Organization (WHO) criteria established in 1994. All women were genotyped for five SNPs (LRP5-1, LRP5-8, LRP5-9, LRP5-20, and LRP5-21) in $L R P 5$, and allele frequencies were statistically analyzed by $x^{2}$ test.

\section{Results}

By the $x^{2}$ test for allele frequencies in group 1 and 2 samples in the study on BMD, two SNPs in TGFB1 (rs1800469 and rs1982073), one each in TGFBR2 (IV$\mathrm{S} 3+21274 \mathrm{~T}>\mathrm{A})$, SMAD2 (rs1787186) and SMAD4 (rs2276163), and two each in IFNB1 (rs1424855 and rs1364612) and IFNARI (rs2253413 and rs2243599) were found to show relatively low $p$ values. Comparison among the 481 samples revealed no significant association between their AdjBMD values and genotypes and between the AdjBMD values and combinations of genotypes for these SNPs $(p>0.05)$.

With 21 (14 known and 7 novel) SNPs in LRP5 (Table 1), we genotyped 77 of the 481 samples to analyze LD within the gene region. We chose nine of the 21 SNPs showing minor allele frequency $>0.2$ to identify LD block and defined a strong LD region between two SNPs, LRP5-7 (IVS7-118T $>$ G) and LRP5-21 (c.3989C > T) (Fig. 1, Table 2). Using 15 SNPs located in the LD block, we identified four common haplotypes with $>5 \%$ frequency, accounting for $89 \%$ of all chromosomes. We then determined three haplotype-tagging SNPs (HT-SNPs) to distinguish these four common haplotypes from each other and to capture the majority of haplotype diversity (Johnson et al. 2001) (Fig. 1). Regarding these three HT-SNPs and their neighboring SNPs, LRP5-10 (IVS10+6T >C), LRP5-11 $($ IVS10 + 100A $>$ G), LRP5-21(c.3989C > T), we expanded genotyping to all 481 samples. We estimated haplotype frequencies and diplotypes among the 481 samples with SNPAlyze. Association study on LRP5 revealed that women with one copy (heterozygotes) or two copies (homozygotes) of haplotype 3 had significantly lower AdjBMD than those without it $(p=0.023)$ (Table 3).

Of five SNPs located within the LD block, three, LRP5-9 (c.2220C > T), LRP5-20 (IVS17-30G > A), and LRP5-21 (c.3989C > T), were identified to show a statistically significant association with AdjBMD values (Table 3). In LRP5-9, women with C/C genotype had a higher AdjBMD value, compared to those with $\mathrm{C} / \mathrm{T}$ and $\mathrm{T} / \mathrm{T}(p=0.022)$. Furthermore, the Spearman's correlation coefficient calculated for the three genotypes revealed that $\mathrm{C} / \mathrm{C}$ women had the highest AdjBMD value, $\mathrm{C} / \mathrm{T}$ women an intermediate value, and $\mathrm{T} / \mathrm{T}$ women the lowest value $(r=-0.118, p=0.009)$, suggesting a dosage effect of alleles on BMD values (Fig. 2). Likewise, women with the G/G genotype for LRP5-20 showed higher AdjBMD than those with $\mathrm{G} / \mathrm{A}$ or $\mathrm{A} / \mathrm{A}$ genotypes $(p=0.039)$ and women with $\mathrm{C} / \mathrm{C}$ for LRP5-21 revealed higher values than those with $\mathrm{C} / \mathrm{T}$ or $\mathrm{T} / \mathrm{T}$ genotypes $(p=0.053)$. In other words, since minor alleles of these three SNPs almost represent haplotype 3, heterozygotes or homozygotes for the minor alleles had significantly lower AdjBMD values than those without
Table 1 Single nucleotide polymorphisms (SNPs) in LRP5 used in the present study. Adenine of the ATG initiation codon is denoted as nucleotide +1 in exon. Intronic SNPs are designated by the intron number. Plus number is counted from guanine of GT splice donor site, and minus number is from guanine of AG splice acceptor site. Allele frequencies were estimated among 77 samples selected from 481 Japanese women

\begin{tabular}{|c|c|c|c|c|c|}
\hline SNPs & Position & Base alteration & $\begin{array}{l}\text { Amino } \\
\text { acid } \\
\text { substitution }\end{array}$ & $\begin{array}{l}\text { Allele frequency } \\
\text { (minor allele) }\end{array}$ & $\begin{array}{l}\text { dbSNP in NCBI } \\
\text { and/or JSNP }\end{array}$ \\
\hline LRP5-1 & Intron 1 & IVS1 $+4689 G>C$ & & $0.453(\mathrm{G})$ & rs312014 \\
\hline LRP5-2 & Intron 1 & IVS1-4340G $>A$ & & $0.060(\mathrm{~A})$ & \\
\hline LRP5-3 & Intron 1 & IVS1-4226T $>C$ & & 0.099 (C) & $\begin{array}{l}\text { rs74744, } \\
\text { JST-IMS137909 }\end{array}$ \\
\hline LRP5-4 & Intron 1 & IVS1-4106G $>A$ & & $0.039(\mathrm{~A})$ & rs 74743 \\
\hline LRP5-5 & Exon 2 & c. $266 \mathrm{~A}>\mathrm{G}$ & Q89R & $0.087(\mathrm{G})$ & \\
\hline LRP5-6 & Intron 6 & $\mathrm{IVS} 6+8 \mathrm{G}>\mathrm{A}$ & & $0.061(\mathrm{~A})$ & \\
\hline LRP5-7 & Intron 7 & IVS7-118T $>$ G & & $0.283(\mathrm{G})$ & rs686921 \\
\hline LRP5-8 & Exon 8 & c. $1647 \mathrm{C}>\mathrm{T}$ & F549F & $0.072(\mathrm{~T})$ & rs545382 \\
\hline LRP5-9 & Exon 10 & c. $2220 \mathrm{C}>\mathrm{T}$ & N740 N & $0.211(\mathrm{~T})$ & $\begin{array}{l}\text { ds2306862, } \\
\text { JST-IMS064599 }\end{array}$ \\
\hline LRP5-10 & Intron 10 & $\mathrm{IVS} 10+6 \mathrm{~T}>\mathrm{C}$ & & $0.039(\mathrm{C})$ & rs4988322 \\
\hline LRP5-11 & Intron 10 & $\operatorname{IVS} 10+100 \mathrm{~A}>\mathrm{G}$ & & $0.293(\mathrm{G})$ & rs576118 \\
\hline LRP5-12 & Intron 10 & IVS10+120T >C & & $0.283(\mathrm{C})$ & rs667126 \\
\hline LRP5-13 & Intron 10 & IVS10-173A $>G$ & & $0.041(\mathrm{G})$ & \\
\hline LRP5-14 & Intron 11 & IVS11+37C $>$ T & & $0.039(\mathrm{~T})$ & $\begin{array}{l}\text { rs2242339, } \\
\text { JST-IMS014541 }\end{array}$ \\
\hline LRP5-15 & Intron 11 & IVS11 $+78 \mathrm{G}>\mathrm{A}$ & & $0.276(\mathrm{~A})$ & $\begin{array}{l}\text { rs689179, } \\
\text { JST-IMS014542 }\end{array}$ \\
\hline LRP5-16 & Intron 16 & IVS16-213T $>C$ & & $0.342(\mathrm{C})$ & rs608343 \\
\hline LRP5-17 & Intron 16 & IVS16-82C $>$ T & & $0.336(\mathrm{~T})$ & $\begin{array}{l}\text { rs607887, } \\
\text { JST-IMS064603 }\end{array}$ \\
\hline LRP5-18 & Intron 17 & IVS17-125G $>A$ & & $0.046(\mathrm{~A})$ & \\
\hline LRP5-19 & Intron 17 & IVS17-63C $>$ T & & $0.046(\mathrm{~T})$ & \\
\hline LRP5-20 & Intron 17 & IVS17-30G $>A$ & & $0.092(\mathrm{~A})$ & \\
\hline LRP5-21 & Exon 18 & c. $3989 \mathrm{C}>\mathrm{T}$ & A1330V & $0.217(\mathrm{~T})$ & JST-IMS080311 \\
\hline
\end{tabular}




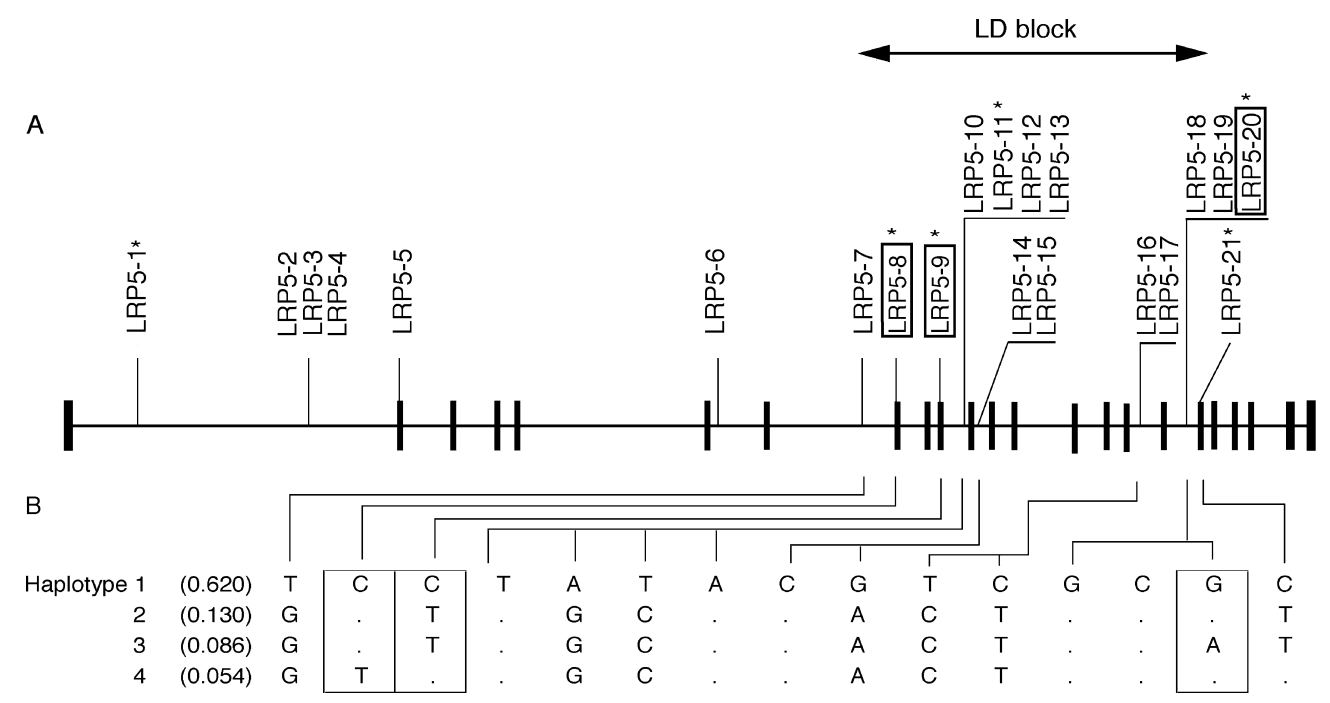

Fig. 1A, B Single nucleotide polymorphisms (SNPs) identified in $L R P 5$, and four common haplotypes constructed based on the SNPs. A Gene structure of LRP5 and SNP sites. Black vertical lines indicate exons. Asterisks and open boxes indicate SNPs used for association study and HT-SNPs, respectively. B Haplotype diversity in the region screened. The four haplotypes account for $89 \%$ of all chromosomes. Dots show the same SNP alleles as those found in haplotype 1, and SNPs in boxes, corresponding to the HT-SNPs above, are those used to distinguish the four common haplotypes. Haplotype frequencies are shown in brackets

them. There was no association between AdjBMD and LRP5-1 (IVS1 + 4689G $>$ C) located outside the LD block (data not shown).

The case-control study on LRP5 and osteoporosis revealed that the allele "T" at LRP5-9 SNP was more frequently deposited in patients $(n=126)$ than in normal control women $(n=131)(p=0.009)$ (Table 4). A similar association was also observed when sampling postmenopausal women with osteoporosis $(n=99)$ and their controls $(n=88) \quad(p<0.01)$. Significant difference $(p=0.001)$ in allele frequency was also observed at a rare SNP, LRP5-8 (c.1647C > T) (Table 4).

\section{Discussion}

Prior to the present candidate gene-oriented association studies between AdjBMD and osteoporosis, we searched and identified SNPs for TGFB1, TGFBR2, SMAD2, SMAD3, SMAD4, IFNB1, IFNAR1, FOS, and LRP5 in the normal Japanese population of women. A total of 481 women having a health checkup were subjects for this study, their BMD values were adjusted by age and BMI, and they were classified by genotype for SNP alleles. There was no significant difference in AdjBMD value among any SNP genotypes of the eight former genes. Although a C- $>$ T SNP (P10L) at +29 in TGFB1 exon 1 was reported to be associated with BMD in postmenopausal Japanese women (Yamada et al. 1998), no such relationship was reproduced in our series of samples. The discrepancy between the two studies may be due to the small sample size of our series, different populations used, and/or different skeletal sites examined for BMD. Alternatively, the C-> T substitution may not generally affect BMD values in Japanese
Table 2 Pairwise linkage disequilibrium (LD) coefficients for nine LRP5 single nucleotide polymorphisms (SNPs) with the allele frequency $>0.20$. LD, expressed as $\left|\mathrm{D}^{\prime}\right|$ and $r$ square, is calculated with genotype data of 77 samples. Pairs in LD, $\left|\mathrm{D}^{\prime}\right|>0.9$ and $r$ square $>0.5$ are shown by italics and bold respectively

\begin{tabular}{|c|c|c|c|c|c|c|c|c|c|}
\hline \multirow[t]{2}{*}{ SNPs } & \multirow{2}{*}{$\begin{array}{l}\left|\mathrm{D}^{\prime}\right| \\
\text { and } \mathrm{r}^{2}\end{array}$} & \multicolumn{8}{|l|}{ SNPs } \\
\hline & & LRP5-7 & LRP5-9 & LRP5-11 & LRP5-12 & LRP5-15 & LRP5-16 & LRP5-17 & LRP5-21 \\
\hline \multirow[t]{2}{*}{ LRP5-1 } & $\left|D^{\prime}\right|$ & 0.001 & 0.219 & 0.162 & 0.062 & 0.066 & 0.100 & 0.152 & 0.219 \\
\hline & $r^{2}$ & 0.000 & 0.011 & 0.009 & 0.001 & 0.001 & 0.006 & 0.014 & 0.011 \\
\hline \multirow[t]{2}{*}{ LRP5-7 } & $\left|\mathrm{D}^{\prime}\right|$ & & 1.000 & 0.966 & 0.967 & 0.966 & 0.962 & 0.925 & 0.954 \\
\hline & $r^{2}$ & & 0.676 & 0.876 & 0.936 & 0.904 & 0.702 & 0.668 & 0.639 \\
\hline \multirow[t]{2}{*}{ LRP5-9 } & $\left|\mathrm{D}^{\prime}\right|$ & & & 1.000 & 1.000 & 1.000 & 1.000 & 1.000 & 1.000 \\
\hline & $r^{2}$ & & & 0.634 & 0.676 & 0.698 & 0.513 & 0.528 & 0.962 \\
\hline \multirow[t]{2}{*}{ LRP5-11 } & $\left|D^{\prime}\right|$ & & & & 1.000 & 1.000 & 0.928 & 0.892 & 0.952 \\
\hline & $r^{2}$ & & & & 0.938 & 0.908 & 0.696 & 0.663 & 0.598 \\
\hline \multirow[t]{2}{*}{ LRP5-12 } & $\left|\mathrm{D}^{\prime}\right|$ & & & & & 1.000 & 1.000 & 0.963 & 0.954 \\
\hline & $r^{2}$ & & & & & 0.968 & 0.759 & 0.724 & 0.639 \\
\hline \multirow{2}{*}{ LRP5-15 } & $\left|D^{\prime}\right|$ & & & & & & 1.000 & 0.961 & 0.955 \\
\hline & $r^{2}$ & & & & & & 0.734 & 0.699 & 0.662 \\
\hline \multirow[t]{2}{*}{ LRP5-16 } & $\left|\mathrm{D}^{\prime}\right|$ & & & & & & & 1.000 & 1.000 \\
\hline & $r^{2}$ & & & & & & & 0.971 & 0.533 \\
\hline \multirow[t]{2}{*}{ LRP5-17 } & $\left|\mathrm{r}^{2}\right|$ & & & & & & & & 1.000 \\
\hline & $r^{2}$ & & & & & & & & 0.549 \\
\hline
\end{tabular}


Table 3 Comparison of adjusted BMD (AdjBMD) values with diplotypes for haplotype 3 (H3)/other haplotypes, and with genotypes for single nucleotide polymorphisms (SNPs) in LPR5 among 481 women

\begin{tabular}{llrll}
\hline $\begin{array}{l}\text { Locus or } \\
\text { SNP site }\end{array}$ & $\begin{array}{l}\text { Diplotype } \\
\text { or genotype }\end{array}$ & $\begin{array}{l}\text { No. of } \\
\text { samples }\end{array}$ & $\begin{array}{l}\text { AdjBMD } \\
\text { value } \\
\left(\mathrm{g} / \mathrm{cm}^{2}\right)\end{array}$ & $p$ value \\
\hline Haplotype & others/others & 377 & $0.442 \pm 0.064^{*}$ & \\
& H3/others & 94 & $0.424 \pm 0.063$ & \\
& H3/H3 & 10 & $0.435 \pm 0.046$ & \\
& H3/H3 & 104 & $0.425 \pm 0.062^{*}$ & 0.023 \\
& $+\mathrm{H} 3 /$ others & & & \\
LRP5-9 & $\mathrm{C} / \mathrm{C}$ & 275 & $0.444 \pm 0.065^{* *}$ & \\
& $\mathrm{C} / \mathrm{T}$ & 166 & $0.432 \pm 0.064$ & \\
& $\mathrm{~T} / \mathrm{T}$ & 40 & $0.425 \pm 0.051$ & \\
& $\mathrm{C} / \mathrm{T}+\mathrm{T} / \mathrm{T}$ & 206 & $0.430 \pm 0.062^{* * *}$ & 0.022 \\
LRP5-20 & $\mathrm{G} / \mathrm{G}$ & 375 & $0.441 \pm 0.064^{* * *}$ & \\
& $\mathrm{G} / \mathrm{A}$ & 93 & $0.426 \pm 0.064$ & \\
& $\mathrm{~A} / \mathrm{A}$ & 13 & $0.434 \pm 0.045$ & \\
& $\mathrm{G} / \mathrm{A}+\mathrm{A} / \mathrm{A}$ & 106 & $0.427 \pm 0.062^{* * *}$ & 0.039 \\
LRP5-21 & $\mathrm{C} / \mathrm{C}$ & 271 & $0.443 \pm 0.065^{* * * *}$ & \\
& $\mathrm{C} / \mathrm{T}$ & 165 & $0.434 \pm 0.065$ & \\
& $\mathrm{~T} / \mathrm{T}$ & 45 & $0.424 \pm 0.049$ & \\
& $\mathrm{C} / \mathrm{T}+\mathrm{T} / \mathrm{T}$ & 210 & $0.432 \pm 0.062^{* * * *}$ & 0.053 \\
\hline
\end{tabular}

Comparisons were done between values with asterisks by Student's $t$ test

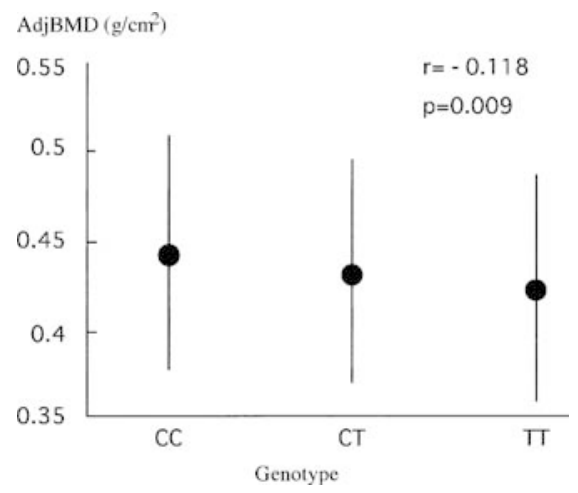

Fig. 2 Correlation between adjusted bone mineral density (AdjBMD) values (mean \pm SD) and three genotypes at LRP5-9 (c.2220C > T) among 481 women. Spearman's correlation coefficient $(r)$ was calculated after categorizing the genotypes CC, TC, and TT among the women into three incremental values, 0 , 1, and, 2 respectively

women. By a genome-wide screening, Koller et al. (2000) provided evidence for a linkage of polymorphic markers to BMD and obtained various LOD scores $(\theta \max =1.87-3.5)$ at four different skeletal regions. In their report, the radial bone we used was not included. Albagha et al. (2002) showed an association between allelic variations in TNFRSF1B and BMD at the femoral neck, while no association was found with lumbar spine BMD. Thus, a specific gene, even if it is associated with BMD, may have different effects on BMD at different skeletal sites. It remains to be seen whether an association is present at other bone regions in our series of samples.

Mice deficient in either Ifnbl or Ifnarl exhibited reduced $\mathrm{BMD}$, resulting from enhanced osteoclast gen-
Table 4 Allele frequency distribution between patients with osteoporosis and normal controls

\begin{tabular}{lllrl}
\hline SNP & \multicolumn{2}{l}{$\begin{array}{l}\text { Allele frequency } \\
\text { (minor allele) }\end{array}$} & $x^{2}$ & $p$ value \\
\cline { 2 - 3 } & Patients & Controls & & \\
\hline LRP5-1 & $0.472(\mathrm{C})$ & $0.511(\mathrm{C})$ & 0.791 & 0.374 \\
LRP5-8 & $0.008(\mathrm{~T})$ & $0.061(\mathrm{~T})$ & 10.731 & $0.001^{*}$ \\
LRP5-9 & $0.302(\mathrm{~T})$ & $0.202(\mathrm{~T})$ & 6.737 & $0.009^{*}$ \\
LRP5-20 & $0.123(\mathrm{~A})$ & $0.084(\mathrm{~A})$ & 2.118 & 0.146 \\
LRP5-21 & $0.302(\mathrm{~T})$ & $0.237(\mathrm{~T})$ & 2.759 & 0.097 \\
\hline
\end{tabular}

* Significant difference

esis (Takayanagi et al. 2002). Under a hypothesis that the two genes as well as FOS might be candidates for osteoporosis, we examined whether a certain genotype is associated with BMD in our series of samples. We studied four SNPs, i.e., rs1424855 and rs1364612 in IFNB1, and rs2253413 and rs2243599 in IFNARI. However, no significant association was observed. Thus, it is less likely that all the eight genes are major genetic determinants for BMD. Since all 481 women in the present study were from a small district in Nagasaki Prefecture, the samples may appear homogeneous with a similar genetic background.

By a survey of LD patterns in LRP5 and its flanking region in the European population, Twells et al. (2003) identified three seeming LD blocks, such as a block between intron 1 and the 5' flanking region, another block between introns 1 and 3 , and the other encompassing from exon 17 to the 3' flanking region. The LD block we identified between LRP5-7 and LRP5-21 (or between intron 7 to exon 18) overlaps with the last LD block found by Twells et al. (2003). Among the four common haplotypes which we constructed within the LD block, haplotype 3 appears significantly associated with AdjBMD, as heterozygotes or homozygotes for it had lower AdjBMD than those without it ( $p$ $<0.023)$. Furthermore, association study on three SNPs in the block gave significant results with low $p$ values $(<0.022-0.053)$. Among them, c. $2220 \mathrm{C}>\mathrm{T}$ at exon 10 is a synonymous substitution, and IVS17$30 \mathrm{G}>\mathrm{A}$ at intron 17 does not seem to affect the splicing process. Although c.3989C $>\mathrm{T}$ at exon 18 -an alanine-to-valine substitution at codon 1330 -is located at the low-density lipoprotein receptor domain class A that contains seven cysteine-rich repeats and highly conserved, negatively-charged amino acids, these two amino acids involved in the substitution are chemically similar. Therefore, it is less likely that any of these SNPs directly alter the LRP5 gene function, suggesting the existence of another significant SNP within the LD block.

The case-control study on LRP5 also gave a positive result, i.e., the T allele at LRP5-9 may predispose to osteoporosis. The finding is compatible with that of the present association study in the general population that homozygotes for the major allele (C) at the SNP site had 
significantly higher AdjBMD than those without it. However, there was no statistical significance between case and control at LRP5-20 or LRP5-21. This may be explained by the small sample size in the case-control study. A recently performed whole genome linkage study supported our results by showing an association of BMD with markers at 11q12-13 (Koller et al. 1998), although other studies never gave any association (Deng et al. 2001; Wilson et al. 2003). In conclusion, both the present association and case-control studies suggest that LRP5 is a BMD determinant and also contributes to a risk of osteoporosis.

Acknowledgements We are grateful to all persons who participated in this study. We also thank to Kazumi Miyazaki, Naoko Takaki, Yasuko Noguchi, and Naoko Yanai for their excellent technical assistance. This study was supported in part by Grant-in-Aid for Scientific Research on Priority Areas (C) "Medical Genome Science, No. 12204010" from the Ministry of Education, Culture, Sports, Science and Technology of Japan.

\section{References}

Albagha OM, Tasker PN, McGuigan FE, Reid DM, Ralston SH (2002) Linkage disequilibrium between polymorphisms in the human TNFRSF1B gene and their association with bone mass in perimenopausal women. Hum Mol Genet 11:2289-2295

Bertoldo F, D'Agruma L, Furlan F, Colapietro F, Lorenzi MT, Maiorano N, Iolascon A, Zelante L, Locascio V, Gasparini P (2000) Transforming growth factor-betal gene polymorphism, bone turnover, and bone mass in Italian postmenopausal women. J Bone Miner Res 15:634-639

Boyden LM, Mao J, Belsky J, Mitzner L, Farhi A, Mitnick MA, Wu D, Insogna K, Lifton RP (2002) High bone density due to a mutation in LDL-receptor-related protein 5. N Engl J Med 346:1513-1521

Deng HW, Xu FH, Conway T, Deng XT, Li JL, Davies KM, Deng H, Johnson M, Recker RR (2001) Is population bone mineral density variation linked to the marker D11S987 on chromosome 11q12-13? J Clin Endocrinol Metab 86:3735-3741

Eisman JA (1999) Genetics of osteoporosis. Endocr Rev 20: 788-804

Gong Y, Slee RB, Fukai N, Rawadi G, Roman-Roman S, Reginato AM, Wang H, Cundy T, Glorieux FH, Lev D, Zacharin M, Oexle K, Marcelino J, Suwairi W, Heeger S, Sabatakos G, Apte S, Adkins WN, Allgrove J, Arslan-Kirchner M, Batch JA, Beighton P, Black GC, Boles RG, Boon LM, Borrone C, Brunner HG, Carle GF, Dallapiccola B, De Paepe A, Floege B, Halfhide ML, Hall B, Hennekam RC, Hirose T, Jans A, Juppner H, Kim CA, Keppler-Noreuil K, Kohlschuetter A, LaCombe D, Lambert M, Lemyre E, Letteboer T, Peltonen L, Ramesar RS, Romanengo M, Somer H, Steichen-Gersdorf E, Steinmann B, Sullivan B, Superti-Furga A, Swoboda W, van den Boogaard MJ, Van Hul W, Vikkula M, Votruba M, Zabel B, Garcia T, Baron R, Olsen BR, Warman ML (2001) LDL receptor-related protein 5 (LRP5) affects bone accrual and eye development. Cell 107:513-523

Grant SF, Reid DM, Blake G, Herd R, Fogelman I, Ralston SH (1996) Reduced bone density and osteoporosis associated with a polymorphic Sp1 binding site in the collagen type I alpha 1 gene. Nat Genet 14:203-205

Hey PJ, Twells RC, Phillips MS, Nakagawa Y, Brown SD, Kawaguchi $\mathrm{Y}$, Cox R, Guochun $\mathrm{X}$, Dugan V, Hammond $\mathrm{H}$, Metzker ML, Todd JA, Hess JF (1998) Cloning of a novel member of the low-density lipoprotein receptor family. Gene 216:103-111
Hirakawa M, Tanaka T, Hashimoto Y, Kuroda M, Takagi T, Nakamura Y (2002) JSNP: a database of common gene variations in the Japanese population. Nucleic Acids Res 30:158-162

Hosoi T, Miyao M, Inoue S, Hoshino S, Shiraki M, Orimo H, Ouchi Y (1999) Association study of parathyroid hormone gene polymorphism and bone mineral density in Japanese postmenopausal women. Calcif Tissue Int 64:205-208

Johnson GC, Esposito L, Barratt BJ, Smith AN, Heward J, Di Genova G, Ueda H, Cordell HJ, Eaves IA, Dudbridge F, Twells RC, Payne F, Hughes W, Nutland S, Stevens H, Carr P, Tuomilehto-Wolf E, Tuomilehto J, Gough SC, Clayton DG, Todd JA (2001) Haplotype tagging for the identification of common disease genes. Nat Genet 29:233-237

Kinoshita A, Saito T, Tomita H, Makita Y, Yoshida K, Ghadami M, Yamada K, Kondo S, Ikegawa S, Nishimura G, Fukushima Y, Nakagomi T, Saito H, Sugimoto T, Kamegaya M, Hisa K, Murray JC, Taniguchi N, Niikawa N, Yoshiura K (2000) Domain-specific mutations in TGFB1 result in CamuratiEngelmann disease. Nat Genet 26:19-20

Koller DL, Rodriguez LA, Christian JC, Slemenda CW, Econs MJ, Hui SL, Morin P, Conneally PM, Joslyn G, Curran ME, Peacock M, Johnston CC, Foroud T (1998) Linkage of a QTL contributing to normal variation in bone mineral density to chromosome 11q12-13. J Bone Miner Res 13:1903-1908

Koller DL, Econs MJ, Morin PA, Christian JC, Hui SL, Parry P, Curran ME, Rodriguez LA, Conneally PM, Joslyn G, Peacock M, Johnston CC, Foroud T (2000) Genome screen for QTLs contributing to normal variation in bone mineral density and osteoporosis. J Clin Endocrinol Metab 85:3116-120

Little RD, Carulli JP, Del Mastro RG, Dupuis J, Osborne M, Folz C, Manning SP, Swain PM, Zhao SC, Eustace B, Lappe MM, Spitzer L, Zweier S, Braunschweiger K, Benchekroun Y, $\mathrm{Hu}$ X, Adair R, Chee L, FitzGerald MG, Tulig C, Caruso A, Tzellas N, Bawa A, Franklin B, McGuire S, Nogues X, Gong G, Allen KM, Anisowicz A, Morales AJ, Lomedico PT, Recker SM, Van Eerdewegh P, Recker RR, Johnson ML (2002) A mutation in the LDL receptor-related protein 5 gene results in the autosomal dominant high-bone-mass trait. Am J Hum Genet 70:11-19

Morrison NA, Qi JC, Tokita A, Kelly PJ, Crofts L, Nguyen TV, Sambrook PN, Eisman JA (1994) Prediction of bone density from vitamin D receptor alleles. Nature 367:284-287

Ohmori H, Makita Y, Funamizu M, Hirooka K, Hosoi T, Orimo H, Suzuki T, Ikari K, Nakajima T, Inoue I, Hata A (2002) Linkage and association analyses of the osteoprotegerin gene locus with human osteoporosis. J Hum Genet 47:400-406

Ota N, Nakajima T, Nakazawa I, Suzuki T, Hosoi T, Orimo H, Inoue S, Shirai Y, Emi M (2001) A nucleotide variant in the promoter region of the interleukin-6 gene associated with decreased bone mineral density. J Hum Genet 46:267-272

Saito T, Kinoshita A, Yoshiura K, Makita Y, Wakui K, Honke K, Niikawa N, Taniguchi N (2001) Domain-specific mutations of a transforming growth factor (TGF)-beta 1 latency-associated peptide cause Camurati-Engelmann disease because of the formation of a constitutively active form of TGF-beta 1 . J Biol Chem 276:11469-11472

Soda MY, Mizunuma H, Honjo S, Okano H, Ibuki Y, Igarashi M (1993) Pre- and postmenopausal bone mineral density of the spine and proximal femur in Japanese women assessed by dualenergy x-ray absorptiometry: a cross-sectional study. J Bone Miner Res 8:183-189

Spotila LD, Rodriguez H, Koch M, Adams K, Caminis J, Tenenhouse HS, Tenenhouse A (2000) Association of a polymorphism in the TNFR2 gene with low bone mineral density. J Bone Miner Res 15:1376-1383

Stewart TL, Ralston SH (2000) Role of genetic factors in the pathogenesis of osteoporosis. J Endocrinol 166:235-245

Takayanagi H, Kim S, Matsuo K, Suzuki H, Suzuki T, Sato K, Yokochi T, Oda H, Nakamura K, Ida N, Wagner EF, Taniguchi T (2002) RANKL maintains bone homeostasis through c-Fos-dependent induction of interferon-beta. Nature 416: 744-749 
Twells RC, Mein CA, Phillips MS, Hess JF, Veijola R, Gilbey M, Bright M, Metzker M, Lie BA, Kingsnorth A, Gregory E, Nakagawa Y, Snook H, Wang WY, Masters J, Johnson G, Eaves I, Howson JM, Clayton D, Cordell HJ, Nutland S, Rance H, Carr P, Todd JA (2003) Haplotype structure, LD blocks, and uneven recombination within the LRP5 gene. Genome Res 13:845-855

Watanabe Y, Kinoshita A, Yamada T, Ohta T, Kishino T, Matsumoto N, Ishikawa M, Niikawa N, Yoshiura K (2002) A catalog of 106 single-nucleotide polymorphisms (SNPs) and 11 other types of variations in genes for transforming growth factor-betal (TGF-beta1) and its signaling pathway. J Hum Genet 47:478-483
Wilson SG, Reed PW, Bansal A, Chiano M, Lindersson M, Langdown M, Prince RL, Thompson D, Thompson E, Bailey M, Kleyn PW, Sambrook P, Shi MM, Spector TD (2003) Comparison of genome screens for two independent cohorts provides replication of suggestive linkage of bone mineral density to 3p21 and 1p36. Am J Hum Genet 72:144-155

Yamada Y, Miyauchi A, Goto J, Takagi Y, Okuizumi H, Kanematsu M, Hase M, Takai H, Harada A, Ikeda K (1998) Association of a polymorphism of the transforming growth factor-betal gene with genetic susceptibility to osteoporosis in postmenopausal Japanese women. J Bone Miner Res 13: $1569-1576$ 